Documentos 



\section{Entrevista com Daniel de Oliveira Gomes}

\section{GOMES, Daniel de Oliveira. Dissonâncias de Foucault. São Paulo: Lumme Editor, 2012.}

\section{$C L^{1}$. Por se tratar de um tema e autor que fogem de debates no nível do senso comum, como você definiria seu público-alvo?}

DG. É um livro de interesse acadêmico e, acho, também geral, para quem tem algum interesse em Michel Foucault, por que não?... Este é um filósofo trabalhado em vários campos do saber e talvez o livro agrade a muitos alunos e estudantes que simpatizam com o autor, nas Universidades. O discurso de Foucault vai desde a medicina, direito, sociologia, até a literatura, que é o campo em que sou mais especializado, juntamente com filosofia. Foucault mapeou, de um modo que apenas ele o faria, todo o pensamento ocidental, toda uma rede que articula discursos ainda hoje, e quando um pensamento se dirige a ele já está enquadrado nesse mapa. Assim, Foucault é um assunto complicado para se ponderar achando-se uma voz do exterior, da Universidade, do Intelectual, por exemplo, pois ele multiplica dissonâncias, e você acaba reverberado nele, mesmo que não queira. Essa foi a dificuldade do meu livro, ser o mais franco possível com o próprio Foucault, porque ninguém precisa ler um manual ou uma historiografia sobre este autor, o melhor é pegar o Foucault na raiz, nos seus textos, diretamente. Então, o problema de escrever sobre Foucault está em aceitar a marginalidade, em se escrever para foucaultianos, de algum modo. Mas ele não escrevia para seus seguidores, não se trata de uma seita, como muitos seguidores querem fazer com o autor. Ele é um autor chave para a academia, para pensar o próprio pensamento nas Humanidades, e não há como passar por qualquer curso universitário sem ter lido algum livro dele. Estou falando de Letras, Sociologia, História, Medicina, Direito, Enfermagem, etc... Outra dificuldade é que quando escrevi o livro, buscava uma editora e um amigo me sugeriu a editora Lumme, de São Paulo, que, no fim, apostou neste trabalho com muito carinho. Há muitos textos e livros harmônicos sobre este autor, por aí, nas livrarias, mas, procurando bem, sempre tem um espaço a mais no mercado editorial para algo meio diferente ou ousado. No meu caso, não é o harmônico, mas firmar a dissonância o que busco.

\section{No seu livro Dissonâncias de Foucault é possível pensar numa questão central na qual as demais reflexões são desenvolvidas. Uma espécie de “ostinato” de onde derivam diferentes possibilidades críticas?}

${ }^{1}$ Entrevistadora: Carla Lavorati (jornalista e mestre em Letras pela UNICENTRO - PR) 
DG. Você fala em “ostinato” que é um tema próprio do campo da música e que Blanchot trabalha, mas podemos simplificar, falando, mais simplesmente, em “experiência melódica”. É o que faço, uma experiência melódica com a escritura, tendo Foucault como apoio. Fazer um trabalho experimental é um tanto complicado, neste caso, pois justamente não teria uma questão central, e se pensasse em uma questão central seria ela o próprio Foucault. Os temas que lido são: ética, sorriso, solidão, poder, autoria, militância, e outros, eis alguns temas meio gerais, em Michel Foucault, que me despertaram interesse para a produção deste livro. Bem, sobre possibilidades críticas, vejo vários modos de se trabalhar com Foucault, desde uma maneira mais didática e instrumental, tentando "aplicar" seus conceitos no mundo, na literatura, na vida, até um modo mais ensaístico e livre que busca despertar novos debates desde os seus livros. Quem sabe, sem perder minha tendência ensaística, eu busco talvez um meio termo entre estas maneiras de ler Foucault hoje em dia. Não quero verificar a utilidade de Foucault para a educação, por exemplo, como virou moda instrumentalista no Brasil, excetuando-se alguns nomes mais brilhantes como Veiga Neto e outros, mas também jamais quereria dizer que a filosofia foucaultiana está antiga, é inaplicável, e deve ser revitalizada ou ser substituída por, por exemplo, Agamben ou Nancy, como outra linha de pesquisadores às vezes acaba por fazer. Foucault é insubstituível. Nele, não se vai simplesmente da teoria para prática. Seria como dizer que podemos pegar um quadro de Van Gogh e colocar no lugar um de Duchamp, pois o pós-impressionismo acabou. Afinal, se trataria de outra coisa, em outro tempo e lugar.

\section{O próprio título, no uso da palavra “dissonâncias”, traz uma carga sugestiva do que podemos esperar para as reflexões no interior do livro. Mesmo que de modo sucinto, fale um pouco sobre essa relação entre o título e a obra.}

DG. A ideia era mais a de verificar um tema específico em Foucault o qual eu chamei de "dissonâncias”, que é um termo que retiro do campo da música. Os debates do presente em torno deste filósofo, tal como venho percebendo, buscam investigar as discrepâncias, as dissonâncias, não de seus conceitos, mas desde a própria postura do autor. Não há tanta possibilidade de ficar vendo incoerências nos conceitos do Foucault, pois eles são, por natureza, muito bem amarrados em um projeto mais amplo, o de produzir uma geografia, uma arqueogenealogia, um mosaico filosófico, digamos. Acredito que meu livro, se tem esta carga sugestiva, vai neste caminho, pois muita coisa já foi dita sobre Foucault e, para mim, não se trata de propriamente criar suplementos, reflexões críticas que simplifiquem o autor. O que é complexo deve ser respeitado em sua natural complexidade e é o que busco operar. Não digo que quero tornar Foucault mais complexo do que já é, não sou louco. Durval Albuquerque Jr. disse sobre meu livro 
que há ali uma “música do pensamento” e me parece que é um pouco por aí, essa música é o próprio Foucault reverberando dissonantemente, digamos, pela minha leitura. Falar dissonantemente sobre Foucault, para mim, é falar ao lado dele e não para criticá-lo. A dissonância é a marca desse autor. Há quem tenha criticado Foucault por isto, como fez o filósofo Jean Baudrillard, em "Esquecer Foucault”, mas de quem discordo. A questão da volatilização do político colocou Baudrillard em outro extremo, em outras preocupações, e não acho certo ele criticar a visão de poder em Foucault simplesmente o colocando como apolítico. Há quem tenha, como Margarete Rago, investigado a possibilidade de aproximar Foucault do anarquismo. Mas não o considero apolítico ou anarquista. Foucault estudava o poder e não o político (trans-político). Há muito a desfrutar de Foucault, o que apreender dele... Este autor foi estudado obsessivamente em uma determinada época, como nos anos 90 e 2000, mas, agora, parece que a academia enjoou ou se recusou a entender certas coisas que ele postula e que a desestabilizava, por um lado. Então é preciso reler Foucault, cada vez mais, para ver se alguma coisa se transforma naquilo que achamos essencial para o conhecimento do presente. Hoje, podemos ler Foucault com olhares que há décadas atrás não era tão possível, mas não se tem feito tanto isto porque muitos acham que é preciso ir além. Só que, com Foucault, é quase sempre como ir “aquém”. Agora é o momento de ler Foucault e não de fugir dele em direção a modismos e teorias consideradas do “além”. Nada há além de Foucault, em certo sentido, para mim, em alguns temas, é como ouvir a voz do sábio na montanha, é preciso voltar à montanha às vezes para ouvir coisas, mas estas coisas são sobre nós mesmos, sobre o nosso interior, o cotidiano do pensar, os poderes que nos afligem e nos levam à montanha. A dissonância está no caminho. Já me acusaram de ter “parado” em Foucault, mas com ele sempre se está dando início a outra coisa, é sempre o começo. A sociedade muda, desarmonizando, as coisas giram, e Foucault também, é a lei da dissonância.

\section{Quais foram as principais dificuldades que você, enquanto autor, encontrou durante a trajetória de elaboração de Dissonâncias de Foucault?}

DG. Escrevi o livro sem nenhum auxílio direto e por puro prazer. Não requeri nenhuma bolsa ou solicitei licença de pós-doutorado para escrevêlo. Em verdade, já venho trabalhando com o autor Michel Foucault há certo tempo; alguns capítulos do livro vêm de um estágio que fiz como professor visitante em Resistência, na Argentina, em 2011. Quando falo em postura dissonante de Foucault é porque essa multiplicidade da dissonância foucaultiana já está viva desde a própria biografia do autor. Foi um dos primeiros intelectuais a morrer de AIDS, etc. Foucault começou seus estudos com um TCC sobre Hegel, tornou-se comunista 
e, estranhamente, cria uma literatura que não segue os preceitos de Marx ou Hegel. Foi professor de psicologia em Lille, perto de Paris, aliás na mesma universidade que me abrigou em estágio doutoral em 2006. Sei que Foucault gostava de Bachelard, foi orientado por Merleau-Ponty, mas nada tem de fenomenológico ou de utópico como estes autores; trabalhou em universidades distantes, procurava palestrar na Tunísia, Polônia ou Brasil, enfim, tudo isto já demonstra um perfil bem periférico e dissonante, na vida do filósofo. Mas, na verdade, me interessei pelo autor há muitos anos, quando ingressei no mestrado e tive de ler “A ordem do Discurso” e "O que é um autor”, com professor Pedro de Souza. Foi como se em minha cabeça tivesse dado um estalo e, do nada, passei a ver o mundo de outro modo. Desde então, ler Foucault diariamente é uma meta e estudá-lo, ainda mais. Este livro que escrevi não tem relação com meu doutorado, apenas um dos capítulos teria a ver. É um livro que vem da idéia de trabalhar a dissonância em Foucault porque essa dissonância é obrigatória para entender o autor e, geralmente, os livros críticos sobre Foucault passam por alto nesse ponto, ou investigam muito didaticamente ou funcionalmente suas ideias. Há uma música em Foucault e ela precisa ser ouvida, por mais difícil que seja.

\section{Pensando de modo mais específico sobre Michel Foucault, qual é, em sua perspectiva, a principal contribuição da leitura crítica empreendida em seu livro para os demais estudos já desenvolvidos?}

DG. Procuro relações, neste livro, com autores de literatura, como Kafka, Pessoa ou Sófocles. Na situação de um pesquisador e um professor de teoria da Literatura, que é minha área de formação e concurso, digo aos meus alunos que trabalhar Foucault com Literatura não se trata de ir apenas “aplicando" os conceitos foucaultianos em objetos literários, estéticos, pois isto seria ir da teoria para prática. Foucault não é só uma teoria filosófica que implicaria numa prática, numa técnica de leitura. Eu procuro, antes, relações onde consiga mostrar que a filosofia de Foucault também não deixa de ser um processo composicional, uma ficção, uma obra de arte, até mesmo uma música. Há quem tenha lido Derrida como “artista” e eu leio Foucault assim. Busco, também, relações com outros filósofos-artistas, os quais citaria, em especial, Nietzsche e Blanchot. Estes autores já estão basicamente bem próximos de Foucault. Outros pensadores e artistas entram no jogo como Searle, Da Vinci e, em especial, Marx, no último capítulo. E o que tem de diferente nesta proposta, isso ainda não sei dizer. Eu apenas sugiro para que o leitor adivinhe ou postule a possível diferença. Mas, não busco a diferença, busco mostrar os efeitos de um debate que já está aí, para todos visivelmente desde os anos 60 . 


\section{Como um estudioso de Michel Foucault, qual a avaliação que você faz das contribuições desse filósofo para pensarmos criticamente a nossa atualidade?}

DG. Este meu novo livro, Dissonâncias de Foucault, deve ter sua importância no sentido de todo esforço que tive e que simboliza ver Foucault dentro de seus próprios paradoxos, sem querer “extrair o leite da pedra”, digamos assim. Acho que não é o caso de ficar buscando contradições no autor para depois explicá-las, se tivessem explicações o próprio Foucault as teria dado. E constantemente quando Foucault era solicitado por algum arguidor, e tentava explicar suas contradições, ele reforçava o paradoxo, a contradição, ao invés de dar a resposta que queríamos. Diziam que ele não explicava seus temas de modo simples, mas o caso é que aquilo que ele estudava nada tinha de simples, ele mergulhou na complexidade extrema de questões que põe sempre a atualidade em xeque, sempre tornam visível essa atualidade em seu "lado B". Assim, eu tento ver Foucault do modo mais sincero possível dentro do labirinto que ele criou. Explicar o labirinto ou dar um mapa não compensa, é destruir o labirinto, é só criar um percurso mais rápido dentro dele. Eu gostaria, com este livro, de mostrar a todos que ler Foucault na nossa atualidade não é um exercício de "reatualização" ou "reaplicação" de uma teoria. Foucault não envelhece e ele sempre foi um autor fugidio, que escorrega, que causa o impacto de uma nota dissonante na melodia, e continuará sendo assim. É sua ética, seu jazz. Mas, este autor está por ser recriado, estudado, investigado em respeito àquilo que na sua época era visto como contraditório. A dissonância às vezes é o que Foucault busca, compondo textos, e não um buraco onde ele teria caído sem querer. Ora, tudo isso me abre as portas para ousar propor o meu livro Dissonâncias de Foucault, porque se houve um filósofo que operou a dissonância no pensamento de seu tempo e que ainda faz efeito hoje em nossos dias, este filósofo foi Michel Foucault. 